\title{
As relações entre as famílias e a equipe do $\mathrm{CRAS}^{\star}$
}

\author{
Roberta Carvalho Romagnoli ${ }^{\text {Orcid, } \star \star}$ \\ Pontificia Universidade Católica de Minas Gerais, Belo Horizonte, MG, Brasil
}

\begin{abstract}
Resumo
Esse texto trata da perspectiva das familias acerca dos trabalhos desenvolvidos em um Centro de Referência em Assistência Social (CRAS) de Belo Horizonte, enfatizando as relações estabelecidas com a equipe. Essa discussão se fundamenta nos resultados parciais da pesquisa financiada pelo CNPq/FAPEMIG que tem como objetivo analisar as relações no território de um Centro de Referência em Assistência Social (CRAS) em Belo Horizonte, enfocando o modo de gestão do trabalho social entre a equipe e com as familias. Esse estudo tem a pesquisa-intervenção como metodologia e as ideias de Deleuze e Guattari como marco teórico. A partir das assembleias, das entrevistas semiestruturadas individuais e coletivas realizadas com a equipe e com as familias, concluimos que a relação da equipe com a família ainda é um desafio no espaço cotidiano do CRAS, bem como a sustentação da promoção social. Esses desafios emergem em pontos como favor, julgamento e responsabilização das mulheres.
\end{abstract}

Palavras-chave: assistência social; pesquisa intervenção; proteção social básica; família; intervenção social.

\section{The relations between families and the team of CRAS}

\begin{abstract}
This article deals with the families' perspectives regarding the work done at the Reference Center for Social Assistance (CRAS) of Belo Horizonte, emphasizing the relations established with the team. This discussion is based on the partial results of the research funded by CNPq/FAPEMIG. The research aims to analyze relationships in the territory of a Reference Center of Social Assistance (CRAS) in Belo Horizonte, emphasizing the social work management style between the team and families. This study uses intervention research as methodology and the ideas of Deleuze and Guattari as theoretical framework. From the semi-structured interviews, collective interviews and meetings with team and family, we conclude that the team relationship with the family is still a challenge in the daily life of the CRAS as well as the sustaining of social promotion. These challenges emerge in points like favor, judgment and responsibility of women.
\end{abstract}

Keywords: social assistance; intervention research; basic social protection; family; social intervention.

\section{Sobre o CRAS e a matricialidade sociofamiliar}

Esse texto trata da perspectiva das famílias acerca dos trabalhos desenvolvidos em um Centro de Referência em Assistência Social (CRAS) de Belo Horizonte, enfatizando as relações estabelecidas com a equipe. Sustentar as tensões existentes, conhecer de forma interventiva e nos deslocarmos junto às famílias usuárias do CRAS foi uma das propostas da pesquisa intervenção que realizamos, buscando uma produção do conhecimento em conjunto com a população pesquisada. Em nosso processo de produção de conhecimento notamos que, para as equipes que atuam no Sistema Único de Assistência Social (SUAS), em particular no CRAS, não é fácil garantir direitos sociais, tampouco convocar a potência nos encontros com os grupos familiares usuários de seus serviços.

O CRAS, localizado em áreas de maior vulnerabilidade e risco social, com o intuito de acompanhar as famílias que vivem nessas condições, é considerado a porta de entrada do SUAS. O SUAS, estabelecido em 2005 em nosso país, é o sistema que faz a gestão da Política Nacional de Assistência Social (PNAS) implantada em 2004, a partir da IV Conferência Nacional de Assistência Social. Essa política tem o intuito de assegurar os princípios presentes na Lei Orgânica de Assistência Social (LOAS) (BRASIL, 1993), documento elaborado a partir da Constituição Federal de 1988, que define os objetivos e as diretrizes da assistência social, a sua forma de orga-

${ }_{\star}^{\star}$ Fonte de Financiamento: CNPq e FAPEMIG.

$\star \star$ Endereço para correspondência: Pontifícia Universidade Católica de Minas Gerais, Faculdade de Psicologia. Rua Dom José Gaspar, 500 - Coração Eucarístico, Belo Horizonte, MG - Brasil. CEP: 30535610.E-mail: robertaroma@uol.com.br nização e a gestão das ações socioassistenciais. Essa lei reforça a assistência social como um sistema descentralizado, com participação popular e financiado pelo poder público, além de consolidá-la como uma política pública, priorizando a proteção à família. Apesar desses ganhos, foi somente no início do ano 2000 que este documento se concretizou em uma política pública de Estado, a PNAS, que corresponde a um conjunto de serviços e programas baseados na organização e hierarquização das ações em rede a partir dos níveis de complexidade do sistema e sob o critério da universalidade, considerando-se a lógica da territorialidade e a centralidade na matricialidade sociofamiliar (BRASIL, 2004).

Essa política, seguindo o modelo da área da saúde, se divide em dois níveis de atenção, a Proteção Social Básica (PSB) e Proteção Social Especial (PSE). A PSB sustenta ações de vigilância social com o intuito de prevenir situações de risco social através das potencialidades e do fortalecimento dos laços afetivos e familiares, possibilitando a inserção dos sujeitos na rede de atendimento, garantindo o acesso às seguranças básicas e aos direitos socioassistenciais. A PSE, por sua vez, corresponde a ações de atendimento socioassistencial destinadas a indivíduos e famílias em situação de violação de direitos (abandono, maus tratos físicos e/ou psicológicos, abuso sexual, substâncias psicoativas, situação de rua, entre outros), intervindo em casos em que há situações de risco com ou sem rompimento dos vínculos familiares, se dividindo em programas de média complexidade e alta complexidade. Nesse contexto, o CRAS se localiza na PSB e suas ações apostam nas poten- 
cialidades dos sujeitos, das famílias e das comunidades. Potencialidades que abordamos em nosso trabalho como potência que pode ou não emergir nas relações que se fazem entre esses grupos e as equipes de trabalho.

Embora a proposta da PNAS pretenda o fortalecimento das capacidades dos indivíduos e das famílias para o enfrentamento da vulnerabilidade, o que é uma grande conquista, sobretudo em um campo marcado historicamente pelo clientelismo e pelo assistencialismo, Oliveira e Heckert (2013) destacam que a noção de vulnerabilidade se funda na desigualdade social e corre o risco de atuar em prol de uma naturalização da miséria para uma parcela da população sem se questionar a própria lógica capitalista que a produz. "A miséria é necessária ao neoliberalismo, pois é do tensionamento provocado pelas desigualdades que ele se alimenta. Os CRAS situam-se estrategicamente nos lugares onde essa miséria habita e atuam gerindo-a, mantendo-a" (OLIVEIRA; HECKERT, 2013, p. 157). Para os autores, o CRAS é um efeito das relações de poder da contemporaneidade, produto do modo biopolítico de gestão das populações, da terceirização da mão de obra, do mercado globalizado e da forma neoliberal de governar. No entanto, esse equipamento e a PNAS que o sustenta não problematizam essas questões, tampouco as contradições estruturais do capitalismo como produtoras de desigualdades sociais, vulnerabilidades e risco. Ainda que os trabalhadores do SUAS devam estar atentos aos efeitos dessa lógica, sobretudo para serem eles próprios produtores de agenciamentos e desvios produtivos em suas atuações com as famílias.

Em qualquer que seja o nível de proteção, a matricialidade sociofamiliar é essencial, priorizando a atenção às famílias e seus membros a partir do território em que se encontram e estabelecendo a família como matriz, sustentáculo das atuações no campo da assistência social, espaço privilegiado e insubstituível de proteção e socialização primárias. Essa matricialidade é colocada pela PNAS e preconizada também pelo SUAS, sistema de gestão dessa política, sustentando atuações junto a esses grupos como uma manobra efetiva contra a setorialização, segmentação e fragmentação dos atendimentos, levando em consideração a família em sua totalidade, como unidade de intervenção (BRASIL, 2004). Ao estudar essa centralidade da família, Gueiros e Santos (2011) assinalam que esse grupo deve ser abordado como um coletivo, respeitando-se as necessidades e especificidades de cada família, compreendendo o momento e a situação familiar na qual se encontram. As autoras entendem que a matricialidade sociofamiliar se faz a partir do vínculo social com a família construído através dos programas e serviços socioassistenciais. Nesse contexto,

A abordagem matricial da família exige que novas formas de enfrentamento das expressões da questão social sejam traçadas para e com a família, de modo integrado e articulado com os serviços socioassistenciais e as demandas que se apresentam a partir de uma interlocução que as considera sujeitos de direitos, agentes sociais [...] (GUEIROS; SANTOS, 2011, p. 86).
Interlocução que não é simples de ser alcançada. Evidenciando a existência de contradições nessa centralidade da família, Teixeira (2010) analisa a presença do referido grupo na trajetória do sistema de proteção social brasileiro, revelando que os avanços dos direitos sociais não rompem com a lógica familista. Desde os anos 90 a família é considerada elemento central na doutrina de proteção social, mas essa centralidade possui o paradoxo de garantia de direitos versus responsabilização. Ou seja, a família é, ao mesmo tempo, o fundamento da sociedade e como tal deve ser protegida pelo Estado, como portadora de direitos e alvo das políticas públicas, e, por outro lado é também detentora de responsabilidades, é responsabilizada, ao lado da sociedade e do Estado, pela proteção à infância e à adolescência e ao idoso. Essa contradição aliada à oferta de uma rede de serviços relegada dentro das restrições dos orçamentos públicos, e à oferta de uma rede socioassistencial não estatal precária, de baixa cobertura e qualidade de serviços e limitada no atendimento da demanda, favorece ainda mais a recaída sobre a família da atenção dos serviços de assistência. Assim, a autora demonstra como a família encontra-se sobrecarregada nesse sistema, assumindo tarefas do Estado, sendo que na relação família versus políticas públicas, não há a diminuição de suas responsabilidades, mas sim um reforço das mesmas. Discutindo também essa responsabilização, Scheinvar (2006) afirma que geralmente o grupo familiar é culpabilizado, de forma particular, por boa parte dos problemas sociais e políticos em nossa sociedade. Focando nos aspectos privados, os casos são particularizados no dia a dia das equipes, privilegiando suas vulnerabilidades e indicando a privatização do social.

Favorecendo ou não a privatização social, com certeza, a matricialidade sociofamiliar não se dá de modo sereno nos equipamentos da assistência social, mas sim deflagra angústias e impasses para os profissionais. A família é em si um grupo que comporta arranjos diversos e passa por várias mudanças ao longo de sua existência. Em um contexto tradicionalmente clientelista e assistencialista, com ações que historicamente transformaram o direito social em favor para os pobres da nossa sociedade, as famílias usuárias do CRAS geralmente não têm condições de fazer frente às situações adversas a que ficam expostos seus membros. Lidando com famílias heterogêneas e em exclusão social, as equipes são chamadas a trabalhar associativamente com a família, esforçando-se para encontrar estratégias de promoção social e de minimização da vulnerabilidade para a proteção dos riscos sociais e pessoais. Nesse contexto, nos propomos a conhecer alguns pontos da relação dessas famílias com o CRAS que pesquisamos, tessituras feitas entre esses grupos, a equipe, o equipamento e o território, apostando na potência da vida, para além da vulnerabilidade designada pela política de assistência social e produzida no bojo das contradições de nossa sociedade e sustentadas pelas desigualdades gerada por essas tensões. Desse modo, rastrear o intensivo na dimensão molecular presente nesses encontros foi um de nossos propósitos. 


\section{Acerca do como conhecemos}

Para conhecer as relações entre as famílias, a equipe, o equipamento e o território, realizamos uma pesquisa-intervenção, com o intuito de perseguir a complexidade e a processualidade e desfazer com as dicotomias teoria-prática, sujeito-objeto, pesquisador-pesquisado. De acordo com Rocha e Aguiar (2003), essa metodologia participativa objetiva tanto a geração de conhecimento quanto a ação transformadora da realidade, através da articulação de análises macropolíticas e micropolíticas. Assim, ao mesmo tempo em que se pesquisa também se realizam intervenções, e o pesquisador tenta contribuir efetivamente com os problemas trazidos pelo campo. Essas intervenções são de ordem micropolítica nas situações cotidianas, que são em si complexas e determinadas por uma heterogeneidade de fatores e de relações. Kastrup (2008) ressalta que nessa relação investigação/ intervenção, de fato ocorre uma produção coletiva de conhecimento que vai se construindo processualmente com a habitação do campo de pesquisa e a implicação do pesquisador. Romagnoli (2014), ao estudar a importância da implicação, para rastrear a singularidades das relações com as instituições que atravessam o campo de pesquisa, insiste no pesquisador como vetor para o mapeamento das forças presentes, dos efeitos dos encontros.

Dessa maneira, realizar uma pesquisa intervenção é rastrear os modelos e as forças presentes no que nos propomos a estudar, desestabilizando, criando zonas de indagações, prestando atenção ao que o campo produz em nós e investigando o que se reproduz e o que cria condições para que o novo apareça. Nesse processo devemos estar atentos à potência instituinte e o que impede sua emergência, perseguindo a desarticulação das práticas e dos discursos instituídos, uma vez que é nesse embate que o conhecimento se faz.

Nessa vertente metodológica, esse texto apresenta parte dos resultados da pesquisa-intervenção que tem como objetivo analisar as relações no território de um CRAS de Belo Horizonte, enfatizando o modo de gestão do trabalho social entre a equipe e com as famílias e buscando favorecer novas formas de expressão nesses grupos. A pesquisa se fez a partir de dois eixos concomitantes de ação desenvolvidos em conjunto com a população pesquisada, compreendendo a formulação de um campo de análise e um campo de intervenção. O campo de análise se constituiu por discussões permanentes da literatura sobre as ideias de Deleuze e Guattari e autores nacionais que trabalham nessa vertente. Estudamos ainda as questões do campo da assistência social e das chamadas famílias em vulnerabilidade social. Para tal, efetuamos encontros quinzenais da equipe de pesquisa. $\mathrm{O}$ campo de intervenção foi sustentado por um projeto de trabalho coletivo com a equipe do CRAS acolhendo as demandas e dificuldades locais e envolvendo discussões acerca da dimensão político-institucional (organização do trabalho, relações da equipe, espaço para participação da família, poder frente aos procedimentos) e da dimensão socioassistencial. Em um segundo momento, esse campo foi composto também pelas famílias cadastradas no equi- pamento e que quiseram participar do estudo. Usamos os seguintes dispositivos de intervenção para a análise das demandas e das implicações: contatos informais, acompanhamento das atividades do serviço, assembleias gerais e entrevistas semiestruturadas com os profissionais e as famílias. Esses dois campos, o de análise e o de intervenção, estavam presentes em todo o percurso da pesquisa, de forma imanente, se interpenetrando a todo o momento.

Nesse cruzamento, os dados foram sendo produzidos coletivamente através das assembleias, dos contatos com o campo e das entrevistas. As assembleias gerais eram realizadas mensalmente ou de acordo com a disponibilidade e a demanda do equipamento e constituídas pela equipe de pesquisa e pela equipe dos profissionais do serviço, composta por quatro técnicos, três assistentes sociais e uma psicóloga e cinco estagiários de serviço social. Além das assembleias gerais, acompanhamos as seguintes atividades do CRAS: grupo de convivências, grupos de mulheres, palestras informativas, reuniões do Programa Bolsa Família e visitas domiciliares. Realizamos seis entrevistas semiestruturadas com a equipe profissional do CRAS e seis entrevistas semiestruturadas com os familiares das famílias cadastradas nos seguintes programas: Programa Maior Cuidado, Grupo de Convivência e Programa Bolsa Família. O Programa Maior Cuidado consiste no atendimento domiciliar a idosos dependentes e semidependentes, realizado por cuidadores de idosos que são contratados, orientados e remunerados pelo município. Os Centros de Convivência do CRAS efetuam o Serviço de Convivência e Fortalecimento de Vínculos, através de grupos de crianças, adolescentes e idosos referenciados. O Programa Bolsa Família, por sua vez, é um programa de transferência direta de renda que beneficia famílias em situação de pobreza, atenuando essa situação através condicionalidades, o que reforça o acesso aos direito básicos na área de educação, saúde e assistência social. As famílias entrevistadas nesses programas foram indicadas pela equipe de profissionais, tendo em vista a disponibilidade e a problemática apresentada. Realizamos ainda uma entrevista coletiva com a presença de apenas três participantes, embora seis tenham confirmado. Tivemos certa dificuldade com as entrevistas com os familiares. Alguns deles não quiseram dar entrevistas, outros marcaram, confirmaram e não compareceram. As entrevistas individuais não acrescentaram muito, pois as famílias tiveram poucas colocações a fazer a respeito do serviço e da equipe, e poucas reflexões acerca do CRAS, por isso resolvemos fazer a entrevista coletiva, na qual os problemas com o equipamento puderam aparecer. Pareceu-nos que no coletivo, os familiares tiveram mais motivação e força para se colocar e questionar.

Atualmente esse CRAS, implantado há cinco anos, possui 1200 famílias cadastradas, embora tenha como estimativa cadastrar 5000 famílias. Nesse contexto, havia um grande interesse da equipe em conhecer a visão das famílias sobre o CRAS e seus serviços. Aliás, essa foi uma das demandas quando começamos o processo de pesquisa, já que essa metodologia trabalha com as questões levantadas pelo campo de pesquisa. Nesse levanta- 
mento inicial constatamos alguns impasses no cotidiano, colocados pelos profissionais e que eles desejavam conhecer com o estudo: o não reconhecimento no território, a apatia da comunidade, a necessidade de incrementar o diálogo entre o serviço social e a psicologia e a pouca demanda de cadastramento dessas famílias. Esse último ponto de incômodo para os profissionais.

O que vimos e escutamos foi analisado através das restituições coletivas realizadas em parceria com a equipe do CRAS. Sobre as restituições, Amador, Lazzarotto e Santos $(2015$, p. 235) indicam que estas "[...] não constituem uma concessão, mas uma estratégia analítica deste modo de pesquisar-intervir que torna necessário o movimento de composição de um coletivo pesquisador". Assim, o processo de restituição é fundamental nessa metodologia de pesquisa, pois nos permite problematizar nossas análises acerca do que vimos e escutamos mediante um processo coletivo, efetuado junto à população que pesquisamos, além de reafirmar o contrato de trabalho com os participantes da pesquisa como salienta Monceau (2013), baseado no pensamento de René Lourau. Com certeza, nossa inserção no campo de pesquisa produziu efeitos sobre os grupos, as pessoas e o serviço, interferindo em seu cotidiano. E foi através dessas interferências que produzimos, em conjunto, a análise das práticas do CRAS que estudamos.

Nas assembleias restituímos nossas análises, discutindo, revendo pontos de vista, agregando conteúdos e leituras, a partir também das colocações dos profissionais. Nesse processo, sentidos foram sendo produzidos coletivamente com a equipe, promovendo questionamentos e deslocamentos, aproximando da dimensão institucional das implicações e das práticas da equipe, na tentativa de criar outras conexões entre eles e com as famílias. Entendemos que agenciar pesquisador e pesquisado, associar teoria e prática, conectar saberes acadêmicos e experiências é produzir indagações que desestabilizam e que podem vir a compor novas realidades. É intervir, colocando em análise as instituições e os processos de subjetivação que constroem o cotidiano dos serviços, no caso, da assistência social na proteção social básica. Os resultados que apresentamos a seguir foram construídos nessa perspectiva e nos permitem conhecer, em parte, as relações estabelecidas pelas famílias com a equipe do CRAS.

\section{(Des)conhecendo as relações entre as famílias usuárias do CRAS e sua equipe}

Conhecer a relação da equipe com as famílias na Proteção Social Básica, um dos objetivos de nosso estudo, é também deixar que essas famílias se coloquem, se posicionem frente às intervenções e ao equipamento, além de pensar nos encontros que se fazem e geram efeitos tanto na equipe como nas famílias. Pensar esses efeitos nos permite rastrear como a inclusão social dos usuários através da matricialidade sociofamiliar está, de fato, acontecendo. Para Deleuze (2002), baseado em Espinosa, filósofo que apostava na produção de uma vida alegre, os encontros são essenciais, uma vez que os corpos se encontram em relação permanente. Relações que promovem encontros, jamais intencionais, uma vez que não escolhemos nos en- contrar. Ao contrário, desde o momento em que somos lançados no mundo estamos sujeitos a encontros. O que, em verdade nos cabe fazer é efetuar o exercício das escolhas, da potência seletiva, cuidando da natureza dos encontros, mediante as experimentações que fazemos na vida.

Desse modo, os encontros que são feitos no CRAS afetam as equipes e as famílias, permitindo ou não a circulação de intensidades, criando deslocamentos e interferências. Esse campo de afetamentos é possível porque os corpos e tudo o que existe se constituem tanto pela potência (intensivo), quanto pelo conjunto de relações que os compõem (extensivo), por partes que se modificam de maneiras infinitas. Estas partes integram nossa subjetividade e se exprimem nas relações que estabelecemos, desfrutando de dimensões distintas, diferenciando-se entre si. Assim, somos todos compostos por partes extensivas, relações e graus de potência que sofrem constantes variações intensivas. Somos, conjuntamente, poder de afetar e de ser afetado, igualdade e singularidade, momento e eternidade, dispostos em um plano de imanência no qual não sabemos de que afetos somos capazes, o que, na verdade, podemos. De acordo com Godinho (2007) no pensamento deleuziano, sustentar o plano de imanência é manter de maneira justaposta e inseparável, a tensão das linhas heterogêneas da realidade que possuem funcionamentos diferentes, no caso a dimensão do intensivo e a dimensão do extensivo, bem como de seus efeitos, que coexistem nos corpos.

Nessa perspectiva, podemos nos perguntar: o que podem essas famílias "vulneráveis"? E esses trabalhadores incomodados? O que circula de intensivo, de potente nesses encontros? Sim, porque não somos separados da nossa relação com o mundo, da dimensão que se forma entre nossas relações, que se define por agenciamentos, movimentos e afetos e que percorre as práticas na assistência social. Dimensão que se forma entre subjetividades e em uma realidade composta por linhas, também em estado de imanência, como atesta Deleuze e Guattari (1996). Linhas duras, que correspondem aos estratos, ao que está organizado e tende a se repetir e atuam homogeneizando, classificando. Linhas flexíveis que permitem a subjetividade captar a exterioridade das forças que atuam sobre ela e linhas de fuga, que ocorrem quando há uma desterritorialização, quando as forças abandonam um estrato feito por determinadas linhas duras, para, através de agenciamentos que emergem nos encontros, efetuar novas composições. As linhas de fuga dependem das forças que dela se apropriam, e indicam que a subjetividade sai dela mesma, e quando essas linhas são ativas, agenciamentos com a alteridade se fazem e ocorre a invenção: traça-se a vida, acompanha-se devires. Essas "[...] três linhas não só coexistem, mas também se transformam, passam uma nas outras" (DELEUZE; GUATTARI, 1996, p. 103) e estão presentes nos encontros que, quando potentes, se desfazem para formar o "entre", desprender intensidades, agenciar e produzir deslocamentos.

Linhas que dão visibilidade ao jogo de forças presentes nas famílias e as tornam, muitas das vezes sem condições de se colocar perante as intervenções feitas pelos 
profissionais. Observamos no contato com esses grupos, durante as atividades desenvolvidas no CRAS e nos dados coletados nas entrevistas, uma grande dificuldade de se posicionar frente ao equipamento. Os familiares raramente conseguiram emitir críticas e refletir sobre os programas do CRAS. "Muito bom, o atendimento deles é muito bom para atender a gente, muito popular com a gente, eu não tenho nada pra reclamar das meninas". Esse tipo de fala, de uma filha cuja mãe frequenta um Centro de Convivência, foi constantemente colocado pelos familiares. Não que no CRAS que tomamos como campo de intervenção e análise as famílias não sejam bem tratadas, mas observamos a manutenção de linhas duras, das partes extensivas assim chamadas por Deleuze (2002), partes que formatam, estratificam e mantêm a marca da dádiva que muito tempo em nossa história sustentou os trabalhos na assistência social, e tornou essas famílias, de fato, impotentes em contato com corpos que queriam "ajudar", mas não permitiam que a potência da vida, o intensivo aflorasse, prerrogativa necessária e imprescindível para que a proposta da atual política de autonomia seja alcançada. Nessa perspectiva, não há autonomia sem que a potência se exerça nos encontros.

O que percebemos é que, em sua maioria, esses grupos ainda sentem que o equipamento faz um favor a eles, uma ajuda que pode cessar a qualquer momento e por isso não podem criticar, tampouco questionar, com receio de perder os benefícios que possuem ou as atividades das quais fazem parte. Isso foi falado explicitamente na entrevista coletiva. Esta visão por parte dos usuários, ainda encontra-se distante da ideia de direito social propagada pela PNAS. Historicamente nesse campo, a permuta de favores e votos reproduzia situações de sujeição que eram "[...] tradicionalmente clientelistas e assistencialistas, [...] ações que transformam o direito em ajuda e doação, sendo que, quem recebe fica devendo um favor e se vê obrigado a retribuir a doação com serviços e votos" (CUNHA, E. P.; CUNHA, E. S., 2002, p. 17) e parece-nos que essa mentalidade ainda é dominante, compondo o estrato da assistência social. Nesse contexto, muitas das famílias ainda se mantém passivas, com certa submissão ao CRAS e com dificuldade de se potencializarem. Esse posicionamento usualmente deixa a equipe sem saber o que fazer para mudar essa condição. Desse modo, a linha dura do assistencialismo e da dependência enlaça os encontros impedindo que estes se façam potentes e a força da vida fica fracionada em segmentos que repetem o que já existia: famílias sem iniciativa e profissionais pretensamente ativos com a missão de resgatá-las da inércia. $\mathrm{Na}$ verdade, a partir de raciocínio de Espinosa na litura de Deleuze (2002), famílias e profissionais - paradoxalmente transitam entre ativos e também passivos. Contudo, nesse contexto, instala-se assim um plano de transcendência que mantém lugares hierárquicos que se sustentam nas dicotomias inércia/capacidade versus salvação/incapacidade permeadas por fortes relações de poder. Plano de transcendência produzido pelo modelo dominante de assistência social, pela mentalidade ainda polarizada e que se sustenta em classificações e oposições, nos distanciando da imanência, da coexistência de tensionamentos inerentes à realidade e à vida.

Ao discutir as metodologias de ação com as famílias na assistência social, Bronzo (2009) pontua que esses grupos, em condições de vulnerabilidade social e de pobreza, desenvolvem atitudes de apatia, resignação, subordinação e dependência, dentre outros, se aprisionando nas armadilhas da escassez. Insistindo em uma identidade grupal calcada na vulnerabilidade e na menos-valia, presas nessas linhas duras que tendem a se reproduzir, essas famílias e esses profissionais podem se encontrar com potência de experimentação debilitada. Precarizados pela exclusão social, circunscrevem a potência da vida em reproduções, clichês dos necessitados e dos provedores, que dicotomizam e tornam binária, a heterogeneidade da vida. Ora tristes, ora ressentidos, ora conformados todos têm sua potência de agir minada. A questão que se coloca é como, no cotidiano do SUAS, fazer com que as conexões se tornem produtivas.

Como vimos, "entre" as subjetividades é que os encontros se fazem deixando transitar afetos. Esses afetos para Deleuze (2002) referem-se às paixões fundamentais que preenchem nossos corpos: a tristeza e a alegria. Tristeza que emerge quando há a diminuição da potência de agir, padecimento que mina a essência, paralisa e me separa do que posso. Alegria que, por sua vez, se dá quando há um aumento da potência de agir, afirmando a existência e me ligando à minha essência. Alegria e tristeza, efeitos de forças externas, dos encontros que se efetuam. Em meio à classificação pelos documentos oficiais de vulnerabilidade e de riscos sociais que se encontram os grupos que acompanhamos, nos arriscamos a perguntar que tipo de encontros é estabelecido e que cuidados ou não à vida estão sendo produzidos nessa dimensão. Nas misturas de corpos que produzem efeitos podemos experimentar bons encontros ou maus encontros. Nos bons encontros, a potência de agir é aumentada e eu experimento um afeto de alegria, ocorre então uma conexão com outro corpo cuja potência se adiciona à minha. Nos maus encontros, a potência de agir é diminuída, encontro-me separado do que posso e eu sou engolido pelas paixões tristes, ocorre então uma conexão com outro corpo cuja potência se opõe à minha.

Deparamos, em nossa pesquisa, com boa parte das famílias separadas do que elas podem, presas em segmentos, atadas às fôrmas da desigualdade social, denotando um funcionamento que, muitas vezes pode ser partilhado pela equipe quando esta tem dificuldade de vê-las como potentes e capazes, embora tenha-se como diretriz da PNAS buscar o fortalecimento das capacidades dos indivíduos e das famílias para o enfrentamento das vulnerabilidades. Ao analisar os termos vulnerabilidade social e risco social em documentos do campo da assistência social, Santos, Roesch e Cruz (2014) investigam também a produção e a circulação dos sentidos dos mesmos entre os psicólogos e os assistentes sociais, evidenciando que estes geralmente se sentem responsáveis por retirar as famílias da situação de vulnerabilidade, deixando de lado a análise de que são 
questões complexas e multideterminadas que levam as famílias a essa condição. Além de desconsiderar, no nosso entender, que esse deslocamento é sempre um movimento coletivo, imanente, que se dá nas misturas de corpos que se agenciam e produzem efeitos potentes e revolucionários. Esse processo jamais ocorre de forma hierárquica e transcendente, a partir de certa superioridade de um dos lados. Moldados pelo seu conhecimento e pela sua classe social, os técnicos correm o risco de inferiorizar e desqualificar as famílias, desconsiderando o contexto em que os modos de vida dos usuários se engendram e efetuando julgamentos e classificações que os distanciam da potência da vida como nos alerta Romagnoli (2015).

A desigualdade social enlaça a todos, naturalizando a miséria, precarizando a vida nessa parcela da população e também em quem com ela trabalha. Esse é um risco que é levantado por Oliveira e Heckert (2013) ao afirmarem que a arte de governar está na própria criação do CRAS, colocando em cena os efeitos da lógica capitalista. Ao realizarem uma análise foucaultiana da emergência desse equipamento e o embate de forças presentes nesse percurso histórico, os referidos autores evidenciam as artes de governar e os efeitos das relações de poder nesse contexto, denunciando como as desigualdades são necessárias para o campo da assistência social, mesmo após a criação da PNAS. Ao estudar a vulnerabilidade social, Monteiro (2011, p. 37) destaca que essa concepção "[...] não considera o caráter estrutural da sociedade capitalista, não problematiza a superação de suas contradições, na medida em que não as considera como produto das desigualdades sociais". Nessa direção, o CRAS em seu funcionamento, também não problematiza essas contradições como produtoras de vulnerabilidades e riscos, focos de sua atuação.

Contradições presentes nas intervenções dos profissionais e que podem compor endurecimentos, deixando circular paixões tristes. Mas como fazer aflorar as paixões alegres, nesse contexto? Viver é a arte de organizar os bons encontros, compor os relacionamentos, formar as potências, experimentar. Devemos estar atentos ao cuidado que estamos produzindo nessas famílias, a que promoção social nós estamos fazendo, pois estes processos podem encobrir práticas morais ou de tutela, resultando em verdadeiros maus-tratos à vida que nada têm a ver com uma construção de cuidado coletiva. Dessa maneira, no cotidiano do SUAS, os profissionais precisam estar abertos para fazer uma composição com as famílias e não uma decomposição, uma vez que a potência de agir varia com as forças que circulam entre os encontros, nas relações, fora dos territórios conhecidos, das formas estabelecidas. Nesse sentido, o grande desafio é como criar um circuito que atue como um dispositivo para formar planos de expansão da vida.

No SUAS, a expansão da vida apresenta-se fragilizada em várias circunstâncias. Em nosso estudo, sem questionar os elementos da realidade social que os colocam em vulnerabilidade, os familiares têm receio de serem lesados pela equipe em certas situações. Quando conseguem se desvencilhar do segmento, do modelo que os dociliza, examinado anteriormente, as famílias usuárias têm uma ideia dos profissionais do CRAS como uma espécie de vigias que estão à espreita de deslizes no cumprimento das condicionalidades, para cortar seus benefícios, sobretudo os benefícios do Programa Bolsa Família. Temor, obediência, subserviência, atitudes que visam manter determinadas posturas que fazem parte dos encontros que se estabelecem sob a égide da sensação de vigilância.

Siqueira e Lino (2013) colocam em análise a política pública de Assistência Social relacionando suas práticas como o exercício do biopoder, definido por Michel Foucault como o poder de fazer viver, de gerenciar a vida, no caso, a vida dessas famílias (FOUCAULT, 1996). Esse controle sobre a vida se exerce na vigilância da moradia, do cuidado destinado às crianças, da higiene, das doenças, do nascimento, da morte. Nessa direção, apontam que os benefícios que as famílias têm medo de perder, conforme escutamos, não são meras "doações", mas sim uma troca com esses grupos que deve, se encaixar nos padrões normatizados, dentre eles, terem os filhos na escola, possuírem assiduidade na unidade de saúde (vacinação), dentre outros. Padrões que conduzem a uma verdadeira alteração de modos de viver desses grupos, em prol dos parâmetros instituídos, imprescindíveis quando a equipe, que não outorga e nem retira esses benefícios que são uma concessão federal, confere e atua para a regularização das situações dos beneficiários, além de efetuar o seu recadastramento. As autoras apontam para o risco de normalização e controle das famílias sem levar em consideração sua singularidade. Nesse sentido, "Assistir muitas vezes é normatizar a vida, os corpos, é tentar consertar os desvios" (OLIVEIRA; HERCKERT, 2013, p. 155). Tanto controle e vigilância podem levar a uma postura, por parte dos especialistas, de que a as pessoas são incapazes de produzir suas próprias estratégias de sobrevivência.

Evidenciamos em nossa pesquisa que a marca da incapacidade circula ainda na articulação com o território e ressoa na equipe, compondo um mau encontro, deixando transitar nas relações estados de paralisação e de reprodução. Nas narrativas dos moradores que residem no bairro em que se localiza o CRAS, apareceram questões da baixa autoestima da comunidade, linhas históricas que foram tecidas ao longo da trajetória da região, considerada inferior quando comparada a regiões vizinhas. Eles são considerados "povo sem estrutura", "pés vermelhos", "pés de pombo", pois antigamente havia lá muito mato e ruas sem calçamento com terra vermelha. Essa terra sujava os pés de quem lá morava que não tinha dinheiro para comprar sapatos e andava descalço, deixado os pés vermelhos, da cor dos pés dos pombos. Esses apelidos depreciativos indicam a pobreza e a falta de recursos, a desqualificação do território, e em alguns momentos aprisionam as forças da comunidade na menos-valia e na inferioridade, compondo formas de exclusão social. Nesse contexto, o lugar que se localiza o CRAS é considerado o mais pobre e violento da região, inclusive muitos dos seus moradores dizem morar em bairros vizinhos quando têm que preencher uma ficha de emprego ou conseguir uma vaga para o filho na melhor escola da região. Fazem isso por acreditar que morar lá é algo que os es- 
tigmatiza, os deprecia. Essa marca circula no território e reverbera nas relações que se estabelecem. Nas conexões com o território, acreditamos que esse desvalor encontra ressonâncias em certas posturas da equipe, que se sente desmotivada e não consegue cumprir todas as suas metas. Esse acoplamento mantém a forma "inferioridade" e impede agenciamentos inventivos, que burlem essas linhas duras, esse modelo de se relacionar.

Essa incapacidade pode circular nas relações que se fazem no CRAS e ser partilhada por todos. Um dos efeitos dessas linhas duras é a própria dificuldade de ocupação dos espaços de representação comunitária, pois essa representação ainda é precária. A ideia de que deveriam levar as questões discutidas para uma instância política em que elas seriam ouvidas surgiu a partir das queixas com relação ao Programa Maior Cuidado. As famílias, na entrevista coletiva realizada, fizeram críticas ao processo de formação do cuidador e à postura do Centro de Saúde. Queixaram-se da falta de comunicação dos profissionais que não passam as informações necessárias, além da desorganização deste programa. Nessa entrevista surge a ideia da liderança comunitária, que lá estava presente, de levar as queixas do Programa Maior Cuidado para o Conselho de Assistência Social. Espaço que até então esta liderança não havia conseguido ocupar, tampouco havia pensado em uma demanda para ser apresentada.

Cabe pontuar que no Programa Maior Cuidado vários conflitos estão presentes na relação dos profissionais do CRAS com os profissionais do Centro de Saúde do território e também com os usuários. Este programa municipal corresponde a uma ação intersetorial para a inserção do idoso na assistência social, obedecendo aos seguintes critérios no domínio da assistência social: ser beneficiário de programa de transferência de renda, ter um único membro da família dispensando os cuidados, o cuidador familiar ser idoso, presença de insuficiência familiar e avaliação socioeconômica compatível. Já no domínio da saúde é necessário: a avaliação funcional do idoso, dificuldade com atividades instrumentais da vida diária, avaliação cognitiva, avaliação de equilíbrio e marcha, internação recorrente e recente e uso de variados tipos de medicamentos. Nesse programa, a intersetorialidade faz emergir uma série de desencontros e queixas colocados pela equipe do CRAS, tais como: falta de apoio dos profissionais as saúde, desqualificação dos serviços prestados por este equipamento e responsabilização da assistência social por todos os cuidados. As famílias também têm queixas acerca da eficácia das ações intersetoriais.

O processo de institucionalização desse programa pela Prefeitura Municipal de Belo Horizonte foi estudado por Rocha (2013), a partir da Análise Institucional de René Lourau, através dos seguintes analisadores, que desvelam pontos de conflito entre forças instituídas e instituintes: o descompasso entre a formulação e implementação do projeto nos territórios, a não escuta dos usuários antes da formulação do projeto, a cisão entre o discurso e a prática da intersetorialidade, a não capacitação dos cuidadores de idosos e a questão velhice e o cuidado, para as famílias e técnicos. A autora evidencia que a ação inter- setorial, com todas as mudanças e flexibilidade que esta exige, ameaça as forças instituídas, imbuídas na conservação do que já existe, impedindo as conexões entre os setores. E, em nossa pesquisa isso foi enunciado pelas famílias usuárias desse programa, que foram entrevistadas.

Alguns familiares relatam ainda que se sentem intimidados e que não procuram o CRAS para se inserir em outros programas, pois receiam viver situações de julgamento, seja pelo seu problema que apresentam, seja pelo modo com que sua família se constitui. Embora a PNAS sustente que no trabalho com a proteção social é preciso considerar outros arranjos familiares que escapem ao modelo da família nuclear, isso não ocorre com flexibilidade no cotidiano, como podemos notar na fala de alguns entrevistados (BRASIL, 2004). Atentas a esses obstáculos que podem sustentar a postura da equipe com os grupos familiares, Gueiros e Santos (2011) defendem a necessidade de que os profissionais que atuam no SUAS ampliem o olhar sobre a família, conhecendo a dimensão social e histórica do grupo e os tratando como, de fato, sujeitos de direito. Para abarcar a complexidade que assola uma família usuária dos equipamentos da política de assistência social é preciso se conhecer a dinâmica interna dessa família e dela com o meio social. Assim, atuar "[...] com famílias significa superar preconceitos, desmistificar a ideologia de família como núcleo natural e padronizado e aprofundar o conhecimento de sua realidade social, adentrando suas vicissitudes, vulnerabilidades e potencialidades" (GUEIROS; SANTOS, 2011, p. 83).

Teixeira (2010) alerta ainda para o risco de a matricialidade retroceder para posturas tradicionais que podem se fundamentar na desconsideração das questões sociais, na- prevalência do metodologismo e na adoção acrítica de referenciais conceituais. Essas posturas podem resultar na patologização das famílias atendidas e em regressões conservadoras no trato com as famílias ampliando ainda mais as pressões sobre as inúmeras responsabilidades que devem assumir. Os familiares entrevistados percebem e denunciam esse plano de forças, embora somente tenham conseguido fazê-lo na entrevista coletiva, nos conduzindo a pensar os poderes que são inerentes aos saberes e as relações, o que ocorre entre as famílias, os profissionais e o CRAS. Romagnoli (2015) também ressalta a importância do conhecimento dos contextos históricos e sociais e das multideterminação da realidade na qual essas famílias estão inseridas. Nesse contexto, examina a crença em um modelo ideal de família por parte da maioria dos agentes sociais que trabalha nas políticas públicas, que utiliza a ideia de família nuclear como referencial, ideal que transcende o cotidiano e tende a igualar os modelos familiares. Esse modelo é responsável pela referência no julgamento das famílias que fogem a esse padrão, desqualificando a singularidade dos grupos cadastrados no CRAS.

$\mathrm{Na}$ tentativa de burlar esse descrédito, que distancia a família do equipamento, como foi colocado pelos entrevistados, é essencial desnaturalizar a ideia de família como algo universal, imutável e sagrado, explorando a sua relação com os diferentes arranjos familiares da atualidade. Desnaturalizar é pensar a complexidade, lançando 
um olhar político, objetivando evidenciar as relações de poder que fazem com que certas coisas tidas como verdadeiras, sejam ditas como algo tomado/produzido como objeto de saber, analisando as práticas discursivas de determinado momento histórico. Ou seja, desnaturalizar é extinguir as origens, as verdades imutáveis e estudar as formas de poder em suas conexões (FOUCAULT, 1996). A construção e sustentação de verdades imutáveis embasadas no saber, verdades que totalizam e homogeneízam corresponde à naturalização, apontada por Scheinvar (2006) e que usualmente circulam entre os técnicos e as famílias precarizando ainda mais a vida presente nesses grupos e impedindo que bons encontros se façam.

Além da naturalização do modelo de família nuclear, certo é que as práticas das políticas públicas também sustentam representações naturalizadas de família, homem e mulher, pai e mãe, como afirmam Meyer, Klein e Fernandes (2012) ao estudar as noções de família em três programas da assistência social localizados na Grande Porto Alegre. As autoras ressaltam que o modelo ideal de família continua sendo referência para a ação dos/ as técnicos/as nesses programas, apesar da assistência social, em seus documentos, insistir em uma concepção mais aberta de família. No dia a dia, um dos efeitos dessas linhas duras, dessas formas cristalizadas, parece ser a "naturalização" da ausência de um homem-pai nos núcleos familiares mais pobres e, sobretudo, sua "desresponsabilização" pela vida das crianças nesse contexto. Essa atitude efetua a sobreposição de parte significativa dos deveres até então definidos como "paternos" por nossa sociedade, sobretudo aqueles vinculados ao provimento do lar, aos já consagrados "deveres maternos". Quase todas as atividades do CRAS têm uma presença majoritária das mulheres contribuindo para a manutenção do imaginário de que o pai é incapaz ou inapto para cuidar das crianças e/ou adolescentes. Apesar das políticas públicas adotem a família como foco de suas ações, convocam, efetivamente, as mulheres-mães para serem suas parceiras, não favorecendo o envolvimento dos pais. Mulheres-mães são ensinadas por muitas instâncias, e constantemente, a responsabilizarem-se pelos seus filhos. Assim, tanto a maternidade, quanto a paternidade passam a ser significadas, instituídas e reguladas pelo Estado.

É preciso refletir sobre esse efeito e desmistificar o conceito de família como algo universal e sagrado, aceitando os diferentes arranjos familiares que escapam ao modelo nuclear, e conseguindo criar vínculos produtivos e inventivos com os grupos em seus mais variados arranjos. É com essa diversidade que os psicólogos e equipes vão atuar, sendo que cada vez mais estes profissionais são convocados a trabalhar associativamente com a família, atentos à singularidade da comunidade em que o profissional está inserido. A PNAS é uma política recente, ainda em construção e para sua consolidação precisamos também conhecer a perspectiva das famílias acerca do seu funcionamento. Como vimos, questões como favor, julgamento e responsabilização das mulheres atravessam a relação

Fractal, Rev. Psicol., v. 30 - n. 2, p. 214-222, 2018 desses grupos com os equipamentos e podem impedir que a vida se exerça, impossibilitando bons encontros que potencialize a todos, tanto da equipe quanto a famílias.

\section{Considerações Finais}

A relação da equipe com a família ainda é um desafio no espaço cotidiano do CRAS, bem como a sustentação da promoção social. A PNAS exige, no nosso entender, a convocação permanente e um esforço coletivo de problematização das questões presentes no cotidiano dessa relação. Postura que tentamos favorecer com nossa pesquisa. Com certeza, é necessário que as famílias sejam parceiras no enfrentamento da exclusão social. Todavia é preciso escutar suas necessidades, acolher suas singularidades e apostar em suas capacidades, para não corrermos o risco de como especialistas, sabermos mais desses grupos que eles mesmos, insistindo em práticas morais e tutelares, que fogem ao propósito dessa política pública.

O desafio permanente, no nosso entender, é construir um modo de fazer e de associar que não atue em prol de uma lógica assistencial, da passividade e da submissão e não da autonomia. Lógica muitas das vezes ainda centrada no indivíduo e em julgamentos moralistas. Para escapar dessa hegemonia, devemos estar atentos a que tipo de vida temos acolhido na assistência social e ao que temos dado passagem nos nossos encontros, se estamos abertos às forças de afirmação da vida ou somente operando para a manutenção do que já existe, da reprodução de modelos. Nessa proposta, uma das saídas para o enfrentamento dessas famílias da fragilidade na qual se encontram, favorecendo o aflorar do intensivo, pode ser o estabelecimento de bons encontros que contribuam a expansão da vida, potencializando equipe e família, uma vez que os efeitos das relações, o que elas compõem ou decompõem são essenciais como nos lembra Deleuze (2002). Já que a realidade não é dada, como geralmente a pobreza e a exclusão nos levam a crer, podemos, através de nossas intervenções, construir paixões alegres que nos conduzam a ações revolucionárias na micropolítica do cotidiano.

\section{Referências}

AMADOR, F. S.; LAZZAROTTO, G. D. R.; SANTOS, N. I. S. Pesquisar-agir, pesquisar-intervir, pesquisar-interferir. Revista Polis e Psique, Porto Alegre, v. 5, n. 2, p. 228-248, 2015. Disponível em: http://seer.ufrgs.br/index.php/PolisePsique/ article/view/58180/pdf_26. Acesso em: 22 mar. 2017.

BRASIL. Presidência da República. Casa Civil. Subchefia para Assuntos Jurídicos. Lei $n^{\circ}$ 8.742, de 7 de dezembro de 1993. Dispõe sobre a organização da Assistência Social e dá outras providências. 1993. Disponível em: http://www.planalto.gov. br/ccivil 03/leis/18742compilado.htm. Acesso em: 21 jun. 2015.

BRASIL. Ministério do Desenvolvimento Social e Combate à Fome. Política Nacional de Assistência Social. Brasília: Secretaria Nacional de Assistência Social, 2004.

BRONZO, C. Vulnerabilidade, empoderamento e metodologias centradas na família: conexões e uma experiência para reflexão. In: BRASIL. Concepção e gestão da proteção social não contributiva no Brasil. Brasília: Ministério do Desenvolvimento Social e Combate à Fome/UNESCO, 2009. p. 171-201. 
CUNHA, E. P.; CUNHA, E. S. M. Políticas públicas sociais. In: CARVAlHO, A. et al. (Org.). Politicas públicas. Belo Horizonte: UFMG/PROEX, 2002. p. 11-25.

DELEUZE, G. Espinosa: filosofia prática. São Paulo: Escuta, 2002.

DELEUZE, G.; GUATTARI, F. Micropolítica e segmentaridade. In: _. Mil Platôs: capitalismo e esquizofrenia. Rio de Janeiro: Editora 34, 1996. v. 3, p. 83-115.

FOUCAULT, M. Microfísica do poder. Rio de Janeiro: Graal, 1996.

GODINHO, A. Linhas de estilo: estética e ontologia em Gilles Deleuze. Lisboa: Relógio d'Água, 2007.

GUEIROS, D. A.; SANTOS, T. F. S. Matricialidade sociofamiliar: compromisso da política de assistência social e direito da família. Serviço Social \& Saúde, Campinas, v. 10, n. 12, p. 73-97, dez. 2011. Disponível em: https://periodicos. sbu.unicamp.br/ojs/index.php/sss/article/view/8634842/3366. Acesso em: 20 mar. 2015.

KASTRUP, V. O método da cartografia e os quatro níveis da pesquisa-intervenção. In: CASTRO, L. R.; BESSET, V. L. (Org.). Pesquisa-intervenção na infância e juventude. Rio de Janeiro: Trarepa/FAPERJ, 2008. p. 465-489.

MEYER, D. E.; KLEIN, C.; FERNANDES, L. P. Noções de família em políticas de 'inclusão social' no Brasil contemporâneo. Revista Estudos Feministas, Florianópolis, v. 20, n. 2, p. 433-449, ago. 2012. Cross ${ }^{\text {Ref }}$

MONCEAU, G. Effets d'une pratique clinique de recherche. In: KOHN. R. C. (Org.). Pour une démarche clinique engagée. Paris: L'Harmattan, 2013. p. 91-104.

MONTEIRO, S. R. da R. P. O marco conceitual da vulnerabilidade social. Sociedade em Debate, Pelotas, v. 17, n. 2, p. 29-40, 2011. Disponível em: http://www.rsd.ucpel.tche.br/ index.php/rsd/article/view/695. Acesso em: 14 mar. 2015.

OLIVEIRA, C. M. C.; HECKERT, A. L. C. Os centros de referência de assistência social e as artes de governar. Fractal: Revista de Psicologia, Niterói, v. 25, n. 1, p. 145-160, jan/abr. 2013. Cross ${ }^{\mathrm{Ref}}$

ROCHA, A. P. L. Cuidado com a velhice: interdisciplinaridade e intersetorialidade. 2013. Dissertação (Mestrado em Psicologia) - Pontifícia Universidade Católica de Minas Gerais, Programa de Pós-Graduação em Psicologia, Belo Horizonte, 2013. Disponível em: http://pepsic.bvsalud.org/pdf/per/v21n3/ v21n3a14.pdf. Acesso em: 5 dez. 2014.

ROCHA, M. L.; AGUIAR, K. F. Pesquisa-intervenção e a produção de novas análises. Psicologia: Ciência e Profissão, Brasília, v. 23, n. 4, p. 64-73, dez. 2003.

ROMAGNOLI, R. C. O conceito de implicação e a pesquisaintervenção institucionalista. Psicologia e Sociedade. Belo Horizonte, v. 26, n. 1, abr. 2014. Cross ${ }^{\text {Ref }}$

ROMAGNOLI, R. C. O ideal de família e seus efeitos no cotidiano dos agentes sociais. In: ROMAGNOLI, R. C.; DIMENSTEIN, M. (Org.). Cotidiano e processos de subjetivação: aprisionamentos e expansões. Vitória: EDUFES, 2015. p. 177-195.

SANTOS, N. L.; ROESCH, D.; CRUZ, L. R. Vulnerabilidade e risco social: produção de sentidos no campo socioassistencial. Revista Jovens Pesquisadores, v. 4, p. 119-127, 2014.
SCHEINVAR, E. A família como dispositivo de privatização do social. Arquivos brasileiros de psicologia, Rio de Janeiro, v. 58, n. 1, p. 48-57, jun. 2006. Disponível em: http://pepsic. bvsalud.org/scielo.php? script $=$ sci_arttext\&pid=S1809. 52672006000100006\&lng=pt\&nrm=iso. Acesso em: 12 set. 2012.

SIQUEIRA, K. O. M.; LINO, M. V. Assistência Social e biopoder: produzindo "vulnerabilidades", prevenindo "riscos" e normalizando as formas de viver. Mnemosine, Rio de Janeiro, v. 9, n. 2, p. 35-53, 2013.

TEIXEIRA, S. M. A família na trajetória do sistema de proteção social brasileiro: do enfoque difuso à centralidade na Política de Assistência Social. Emancipação, Ponta Grossa, v. 10, n. 2, p. 535-549, 2010.

Recebido em: 13 de julho de 2015 Aceito em: 30 de junho de 2017 